NBER WORKING PAPER SERIES

\title{
TAX DISTORTIONS AND GLOBAL CLIMATE POLICY
}

\author{
Mustafa H. Babiker \\ Gilbert E. Metcalf \\ John Reilly \\ Working Paper 9136 \\ http://www.nber.org/papers/w9136 \\ NATIONAL BUREAU OF ECONOMIC RESEARCH \\ 1050 Massachusetts Avenue \\ Cambridge, MA 02138 \\ September 2002
}

The authors gratefully acknowledge the support of the Joint Program on the Science and Policy of Global Change, funded through a government-industry partnership including the US Department of Energy's Integrated Assessment Program in the Office of Biological and Environmental Research (BER), (DE-FG0294ER61937), the US Environmental Protection Agency (X-827703-01-0), and a group of corporate sponsors from the United States and other countries. In addition, the second author gratefully acknowledges support from the National Science Foundation through a grant to the NBER (NSF SBR-9811324). An early version of this paper was prepared for the Fourth Annual Conference on Global Economic Analysis at Purdue University, held in June, 2001. David Fu provided excellent research assistance on this project. Don Fullerton and two referees have provided valuable comments on a previous draft of this paper. The views expressed in this paper are those of the authors and not necessarily those of the National Bureau of Economic Research.

(C) 2002 by Mustafa H. Babiker, Gilbert E. Metcalf and John Reilly. All rights reserved. Short sections of text, not to exceed two paragraphs, may be quoted without explicit permission provided that full credit, including (C) notice, is given to the source. 
Tax Distortions and Global Climate Policy

Mustafa H. Babiker, Gilbert E. Metcalf and John Reilly

NBER Working Paper No. 9136

September 2002

JEL No. H2, Q2

\section{ABSTRACT}

We consider the efficiency implications of policies to reduce global carbon emissions in a world with pre-existing tax distortions. We first note that the weak double-dividend, the proposition that the welfare improvement from a tax reform where environmental taxes are used to lower distorting taxes must be greater than the welfare improvement from a reform where the environmental taxes are returned in a lump sum fashion, need not hold in a world with multiple distortions. We then present a large-scale computable general equilibrium model of the world economy with distortionary taxation. We use this model to evaluate a number of policies to reduce carbon emissions. We find that the weak double dividend is not obtained in a number of European countries. Results also demonstrate the point that the interplay between carbon policies and pre-existing taxes can differ markedly across countries. Thus one must be cautious in extrapolating the results from a country specific analysis to other countries.

Mustafa H. Babiker

Joint Program on the Science and Policy of Global Change Massachusetts Institute of Technology

Cambridge, MA 02139
Gilbert E. Metcalf

Department of Economics

Tufts University

Medford, MA 02155

and NBER

gilbert.metcalf@tufts.edu

John Reilly

Joint Program on the Science and Policy of Global Change

Massachusetts Institute of Technology

Cambridge, MA 02139 


\section{Introduction}

The past ten years has seen a tremendous amount of interest in the interaction between distortionary taxation and optimal environmental policy. Much progress in our understanding of this interaction has occurred, and general equilibrium modeling has played a key role. A popular but often ill-defined concept is the "double dividend," the idea that imposing an environmental tax can both improve economic performance and the environment. The attraction of a double dividend arose in the 1980s from the conjunction of an increased concern about climate change and the consequent need for a policy response on the one hand and the U.S. federal budget deficit on the other hand. Environmental taxes appeared desirable given both these concerns.

Goulder [23] provides a useful taxonomy of double dividends as well as an explanation of their appeal. ${ }^{1}$ Goulder distinguishes a "strong" and "weak" double dividend. A strong double dividend occurs when welfare is increased in response to an environmental tax regardless of the improvement in environmental quality. Given the great difficulties associated with quantifying the economic benefits of an improved environment, a strong double dividend is appealing in that a case can be made for an environmental tax without having to worry about the magnitude of the environmental gains. It is possible for welfare (net of environmental improvements) to increase in response to a green tax reform if the environmental tax revenues are used to lower a

\footnotetext{
${ }^{1}$ See Bovenberg [12] for an update to that literature.
} 
particularly egregious distorting tax. This simply points out the obvious fact that any tax reform to replace a highly distorting tax with a less distorting taxes is, in general, a good idea. See Bovenberg and Goulder [13] for further discussion of this point. We find, as discussed below, that a strong double dividend is unlikely for the climate policy targets in the Kyoto Protocol.

A "weak" double dividend occurs when the welfare improvement from a tax reform where environmental taxes are used to lower distorting taxes is greater than the welfare improvement from a reform where the environmental taxes are returned in a lump sum fashion. A general consensus has emerged that the weak double dividend is an uncontroversial idea; it just says that lowering a distorting tax is better than simply handing out the money. We show below, however, that in an economy with multiple distortions, a weak double dividend need not occur. Moreover, we argue that climate policies under consideration in response to global warming will likely not provide a weak double dividend in a number of European countries.

We proceed as follows. In the next section, we provide some intuition for why a weak double dividend need not hold. We then turn in the third section to a computable general equilibrium (CGE) model. Most general equilibrium models typically focus on a single country. The MIT Emissions and Policy Analysis (EPPA) model allows us to carry out cross-country comparisons as well as analyses that evaluate international policy schemes (e.g. Kyoto) in a world with pre-existing 
taxation. Section 4 provides results from a number of experiments we carry out using the model. Section 5 concludes.

\section{Must a Weak Double Dividend Occur?}

A weak-double dividend arises when welfare is increased by using environmental tax revenues to lower distorting taxes as opposed to returning the revenues in a lump-sum fashion. Economists view this as an uncontroversial proposition. ${ }^{2}$ In this section, we provide an intuitive demonstration that the weak double-dividend need not hold in general.

The following simple model will help explain the intuition. ${ }^{3}$ Consider an economy with a representative agent whose utility is a function of consumption of two goods (X, Y), leisure (V) and environmental quality (E):

$$
\mathrm{U}(\mathrm{X}, \mathrm{Y}, \mathrm{V} ; \mathrm{E})
$$

Environmental quality falls with increased amounts of pollution $(Z)$ which is associated with the production of one of the two commodities (good Y for specificity). Consumers maximize utility subject to the budget constraint

$$
\mathrm{p}_{\mathrm{X}} \mathrm{X}+\mathrm{p}_{\mathrm{Y}} \mathrm{Y}=\mathrm{L}+\mathrm{T}
$$

where $\mathrm{p}_{\mathrm{X}}$ and $\mathrm{p}_{\mathrm{Y}}$ are the consumer prices for $\mathrm{X}$ and $\mathrm{Y}$, the gross wage rate equals 1 (labor is taken as the numeraire good) and $\mathrm{T}$ is a lump-sum transfer. Leisure and labor

\footnotetext{
${ }^{2}$ Starrett [39] notes, for example, that "this result is quite general and reflects the fact that we are always better off using the green tax revenue to reduce some other distorting tax rather then [sic] (for example) returning it in a lump sum manner." (p. 36) See also the discussion in Goulder [23] on pages 159-161.

${ }^{3}$ See Babiker, et al. [5] for a full model and some numerical results.
} 
sum to a fixed time endowment. Consumer prices are related to producer prices as follows:

$$
\begin{gathered}
\mathrm{p}_{\mathrm{X}}=1+\mathrm{t}_{\mathrm{X}} \\
\mathrm{p}_{\mathrm{Y}}=\mathrm{q}_{\mathrm{Y}}\left(\mathrm{t}_{\mathrm{Z}}\right)\left(1+\mathrm{t}_{\mathrm{Y}}\right)
\end{gathered}
$$

where $t_{x}$ and $t_{y}$ are commodity taxes levied on goods $X$ and $Y$, respectively, to raise revenue, and $t_{\mathrm{z}}$ is an environmental tax levied on $\mathrm{Z}$. Initially $\mathrm{t}_{\mathrm{z}}$ equals zero. Increases in the environmental tax raise the marginal cost - and hence the producer price - of Y, denoted by q. The government budget constraint is given by

$$
t_{X} X+t_{Y} q_{Y} Y+t_{Z} Z=T
$$

again noting that $t_{\mathrm{z}}$ initially equals zero.

Consider the options in Table 1 for effecting a revenue neutral tax reform in response to a new environmental tax initiative $\left(\mathrm{t}_{\mathrm{z}}\right)$ :

\begin{tabular}{|c|c|c|}
\hline \multicolumn{3}{|c|}{ Table 1: Revenue Neutral Tax Policies } \\
\hline Policy & Hold Fixed & Adjust \\
\hline 1 & $t_{X}, t_{Y}$ & $T$ \\
\hline 2 & $t_{Y}, T$ & $t_{X}$ \\
\hline 3 & $t_{X}, T$ & $t_{Y}$ \\
\hline
\end{tabular}

A weak double dividend occurs when the welfare gain from policy 2 (or 3 ) is greater than the welfare gain from policy 1.

A weak double dividend can be easily shown to occur if commodity Y is untaxed in the model above. Policy 1 raises a tax on pollution and uses the revenue to lower a lump-sum tax. ${ }^{4}$ Policy 2 raises a tax on pollution by the same amount as in

\footnotetext{
${ }^{4}$ Or equivalently, it increases a lump-sum subsidy.
} 
policy 1 but returns the tax revenue by reducing the tax on X. To see that a weak double dividend must hold, consider policy 1 run in reverse: lower a tax on pollution and finance this tax reduction by increasing a lump-sum tax. Call this policy $1 \mathrm{r}$ (for reverse). Now run policy 2 followed by policy $1 \mathrm{r}$. This is equivalent to a policy which lowers the tax on $\mathrm{X}$ and raises a lump-sum tax in a revenue neutral manner. This policy experiment clearly raises welfare from which we can conclude that the welfare gain from policy 2 exceeds the welfare gain from policy 1 . The weak double dividend in this simple model in which there is only one distorting tax (other than the tax on the polluting good) is simply a restatement of the principle that lump-sum taxes are preferred to distortionary taxes on efficiency grounds.

To see why a weak double dividend need not hold more generally, assume that $p_{Y}>>p_{X}>0$ (perhaps because of a high rate of taxation on $Y$ relative to $X$ ) and that utility is weakly separable between leisure and the two commodities and that the subutility function over commodities is homothetic. An implication of this preference structure is that the optimal commodity tax structure (ignoring the environmental problem) is one of uniform commodity taxes (Deaton [17]). Thus, ignoring environmental considerations, a revenue neutral tax reform would be welfare enhancing if it reduced the difference between $p_{Y}$ and $p_{X}$. With this preference structure, it would be preferable on efficiency grounds to implement an environmental tax reform that returned the revenue lump-sum rather than in a way that increased the $\mathrm{p}_{\mathrm{Y}} \mathrm{p}_{\mathrm{X}}$ differential. In other words, policy 1 in Table 1 above would be preferred on 
efficiency grounds to policy 2 since this latter policy increases $\mathrm{p}_{\mathrm{Y}}-\mathrm{p}_{\mathrm{X}}$. The policy prescription from this simply analysis is that in an economy with multiple distortions, one must choose carefully which distortions to reduce, or one can do worse than a lump sum redistribution. Put simply, there is no theoretical basis to conclude that a weak double dividend must exist. We next demonstrate in a large-scale CGE model that climate policies under consideration in response to global warming will likely not provide a weak double dividend in a number of European countries.

\section{Empirical Estimation of Revenue Recycling}

Empirical investigations of the potential importance of the double dividend in climate policy date to the early 1990s, with several different types of models used (see for example Shackelton, et al. [38]). The models include Keynesian-type macroecononomic models such as the DRI and LINK models, econometrically estimated general equilibrium models (e.g. DGEM, Jorgenson and Wilcoxen [32]), and parameterized CGE models (e.g. Goulder [22]; Boyd, et al. [15]). A comparison of these early results for the US (Hourcade, et al. [25]) showed widely varying results. The Keynesian-type economic models found very large strong double-dividends from investment tax credits. A problem with the econometrically based Keynesian-type macroeconomic models, however, is that theoretical underpinnings of the estimated relationships are weak. DGEM results found strong double-dividends from corporate income tax cuts as did the DRI model. In contrast, the parameterized CGE model of Goulder did not find evidence of strong double dividends; recycling revenue to the 
investment tax credit ended up just balancing losses from the carbon tax itself. These results were in terms of discounted present value of GDP and thus do not directly measure welfare.

Later reviews (Goulder [22]; Parry [34]; Bovenberg [12]) have helped to clarify issues surrounding the Double Dividend. Since then there has been more empirical analysis and speculation on the existence of the double-dividend in other countries, particularly Europe, as reviewed by Hourcade and Shukla [26]. One CGE analysis posited a strong double dividend in Europe (Carraro and Soubeyran [16]) but another empirical analyses using a CGE model suggested little evidence of a strong double dividend in France (Bernard and Vielle [11]). A Keynesian-type model estimated for Europe systematically found a large strong double dividend (Barker [9]). There has been very little investigation of the potential double-dividend benefits in developing countries, in part perhaps, because developing countries have not agreed to an emissions cap. An exception is Boyd and Ibarrarian [14] who investigate the potential for a double dividend in Mexico, should Mexico seek to control emissions, but find little support for its existence except under unusual circumstances.

To comparably study the existence of a double-dividend in different countries, we employ the Emissions Prediction and Policy Analysis (EPPA) model, a recursive dynamic multi-regional general equilibrium model of the world economy that has been developed for analysis of climate change policy (see, for example, Babiker, et al. [1]; Babiker, et al. [7]; Babiker, et al. [8]; Ellerman and Sue Wing [19]; Babiker and 
Eckaus [2]; and Babiker and Jacoby [3]. Previous versions of the model have been used extensively for this purpose (e.g., Jacoby, et al. [29]; Ellerman and Decaux [18]; Jacoby and Sue Wing [30]; and Reilly, et al. [36]). The current version of EPPA is built on a comprehensive energy-economy data set $\left(\right.$ GTAP4-E $\left.{ }^{5}\right)$ that accommodates a consistent representation of energy markets in physical units as well as detailed accounts of regional production and bilateral trade flows. The base year for the model is 1995 and it is solved recursively at 5-year intervals. A full documentation of EPPA is provided in Babiker, et al. [6]. In this paper, we use a new version of the model (EPPA-EU) including a breakdown for the European Union. The reference case for Europe in EPPA-EU is presented and compared with other economic models in Viguier, et al. [40]. As significant advantage of this approach compared with previous work is that a common method and data set is applied to all countries and the crosscountry results are thus comparable. As reviewed above, the existing empirical studies are for the most part based on single country models.

\section{III-1. EU Disaggregation}

EPPA-EU extended the current version of EPPA by bringing in a detailed breakdown of the EU and incorporating an industry and a household transport sectors for each region. The regional, sectoral, and factors aggregation shown in Table 2, together with the substitution elasticities in Table 3 completely specify the benchmark equilibrium.

\footnotetext{
${ }^{5}$ For description of the Global Trade Analysis Project (GTAP) database see Hertel [24].
} 
The European Union is disaggregated into 9 countries and 1 region representing the Rest of Europe (ROE). Four out of the 9 EU countries (France, Spain, Italy, and the Netherlands) were aggregated together with ROE in the GTAP4E database. We disaggregated this region using data from the GTAP-5 Pre-release that provides a complete disaggregation of the EU. ${ }^{6}$ To accomplish this task we developed an optimization algorithm that uses the economic structure of these 4 countries in GTAP-5 Pre-release while imposing the output, demand, and trade balances for their corresponding aggregate region in GTAP4-E. This allowed us to leave unchanged all other regions of the standard EPPA based on GTAP4-E.

\section{III-2. Transportation Sector Disaggregation}

A second change in this version of the model is the disaggregation of the transportation sector. With transportation disaggregated, there are nine output sectors for each of the 22 regions in EPPA-EU, as shown in the left-hand column of Table 2. The EPPA model also includes future or "backstop" sources of fuels and electricity, but they do not play a significant role in this analysis which looks only out to 2010 . Eight of the production sectors follow the standard EPPA definitions. The GTAP database does not include a separate transportation sector within industry, nor does it contain a separate category for private automobile services in the household sector. We followed the methodology developed by Babiker, et al. [1] for the United States to

\footnotetext{
${ }^{6}$ Though GTAP-5 Pre-release has all 9 of these countries broken out we chose to focus on disaggregating only the 4 largest of these countries.
} 
break out transportation from EPPA's Other Industry sector and to create a household own-supplied transportation sector (i.e. private automobiles).

\begin{tabular}{|l|l|l|l|}
\hline \multicolumn{4}{|c|}{ Table 2. Dimensions of the EPPA-EU Model } \\
\hline Production Sectors & Name & Countries and Regions & Name \\
\hline \multicolumn{1}{|c|}{ Non-Energy } & & \multicolumn{1}{|c|}{ Annex B } & \\
\hline 1. Agriculture & AGRI & United States & USA \\
\hline 2. Energy-Intensive Industries & EINT & Japan & JPN \\
\hline 3. Other Industries and Services & OIND & Europe & EEC \\
\hline 4. Transportation & TRAN & Denmark & DNK \\
\hline \multicolumn{1}{|c|}{ Energy } & & Finland & FIN \\
\hline 5. Crude Oil & OIL & France & FR \\
\hline 6. Natural Gas & GAS & Germany & DEU \\
\hline 7. Refined Oil & REFOIL & Italy & ITA \\
\hline 8. Coal & COAL & Netherlands & NLD \\
\hline 9. Electricity & ELEC & Spain & ESP \\
\hline \multicolumn{1}{|c|}{ Future Energy Supply } & & Sweden & SWE \\
\hline 10. Carbon Liquids & & United Kingdom & GBR \\
\hline 11. Carbon-Free Electric & & Rest of EU & \\
\hline & & Other OECD & ROE \\
\hline Households (Consumers) Sector & H & Former Soviet Union & OOE \\
\hline & & Central European Associates & FSU \\
\hline Primary Factors & & \multicolumn{1}{c|}{ Non-Annex B } \\
\hline 1. Labor & L & Brazil & \\
\hline 2. Capital & K & China & BRA \\
\hline 3. Fixed Factors for Fuel & & India & CHN \\
\hline And Agriculture & & Energy Exporting Countries & IND \\
\hline & & Dynamic Asian Economies & DAE \\
\hline & & Rest of World & ROW \\
\hline${ }^{a}$ Includes Austria, Belgium, Greece, Ireland, Luxembourg, and Portugal. & \\
\hline
\end{tabular}




\begin{tabular}{|c|c|c|c|}
\hline \multicolumn{4}{|c|}{ Table 3. Model Parameters } \\
\hline Parameter & Description & & Value \\
\hline$\sigma_{E R V A}$ & $\begin{array}{l}\text { Elasticity of substitution between energy resource con } \\
\text { (agriculture only) }\end{array}$ & osite and value-added & 0.6 \\
\hline$\sigma_{E R}$ & Substitution between land and energy-material bundle & agriculture only) & 0.6 \\
\hline$\sigma_{A E}$ & Substitution between energy and material composite & griculture only) & 0.3 \\
\hline$\sigma_{V A}$ & Substitution between labor \& capital ${ }^{a}$ & & 1 \\
\hline $\boldsymbol{\sigma}_{E N O E}$ & Substitution between electric and non electric energy & & 0.5 \\
\hline$\sigma_{E N}$ & Substitution among non-electric energy ${ }^{b}$ & & 1 \\
\hline$\sigma_{G R}$ & Substitution between fixed factor and the rest of input & & 0.6 \\
\hline$\sigma_{E V A}$ & Substitution between energy and value added compos & & 0.4 \\
\hline$\sigma_{D M}$ & Armington substitution between domestic and imports & & 3 \\
\hline$\sigma_{M M}$ & Armington substitution across imports: & $\begin{array}{l}\text { - Non energy goods } \\
\text { - Energy goods }\end{array}$ & $\begin{array}{l}5.0 \\
4.0\end{array}$ \\
\hline$\sigma_{C S}$ & Temporal substitution between consumption and savi & & 1 \\
\hline$\sigma_{C}$ & Substitution across consumption goods ${ }^{f}$ & & \\
\hline G0 & Labor supply annual growth rate in efficiency units: & $\begin{array}{l}\text { - Developed countries } \\
\text { - Developing countries }\end{array}$ & $\begin{array}{c}1-3 \% \\
2.5-6 \%\end{array}$ \\
\hline \multicolumn{4}{|c|}{$\begin{array}{l}{ }^{a} \text { Except nuclear in which it is } 0.5 \text {. } \\
{ }^{b} \text { Except for electricity where coal and oil generation substitute at } 0.3 \text { among themselves and at } 1.0 \text { with } \\
\text { gas. } \\
{ }^{c} \text { Except energy intensive and other industry where it is } 0.5 \text {. } \\
{ }^{d} \text { Except Electricity where it is } 0.3 \text {. } \\
{ }^{e} \text { Except refined oil (6) and electricity (0.5). } \\
\text { f Varies across countries and is updated with income recursively to reflect income elasticities based on an } \\
\text { econometrically estimated equation. See Babiker et al. } 2001 \text { for details. }\end{array}$} \\
\hline
\end{tabular}

The basic approach for the TRANS sectors is to use GTAP's trade and transport sector that combines transport with trade margins in combination with data from Input-Output tables produced by the European statistical office (Eurostat). These tables provide the data to disaggregate trade margins from transportation for each European country. For the other regions in the model, we used the US input-output coefficients from Babiker, et al. [1]. The TRANS industry supplies transportation services (both passenger and freight) to other sectors and to households. 
We have also made adjustments directly to the Household $(\mathrm{H})$ sector to represent own-supplied transportation services, primarily that provided by personal automobiles. Households produce transportation services for their own consumption using inputs from the Other Industry Products (OIND) and Refined Oil sectors. Consumption expenditure of private households reported by Eurostat [20] and energy statistics from the International Energy Agency ([27, [28] along with the coefficients reported in Babiker, et al. [1] were used to separate the household purchases that are part of household production of transportation from other household purchases.

The new breakout yields a sector of own-supplied personal transportation (private automobiles) separate from other household activities, and a separate transportation sector in industry that supplies transport services to both industry (i.e., freight transportation and any passenger transportation purchased by business) and households (purchased transportation service, mainly passenger transportation services such as air and rail service). Services from private automobiles involve inputs from OIND that include the automobile itself, repairs, insurance, parking, and vehicle fuel from the REFOIL sector. The procedure involves allocating the total household use of OIND and REFOIL between household transportation and other household uses.

\section{III-3. Incorporating Labor Leisure Choice}

Critical to the investigation of the distortionary effect of taxation are the effects of factor taxes on factor usage. We have adjusted the Social Accounting Matrices for OECD regions in the database to account for the leisure component in the utility 
function, to represent the labor-leisure tradeoff and thus the effect of taxes on labor supply. The standard version of EPPA models labor as inelastically supplied. Based on the literature (e.g., Goulder [22]; Fullerton and Metcalf [21]; and Bovenberg [12]) we have assumed a leisure-labor ratio of 0.25 , and an uncompensated labor supply elasticity of 0.25 . We investigate the sensitivity of this latter assumption below.

\section{III-4. Incorporating factor taxes and non-energy consumption taxes}

To correctly assess the economic impacts of climate change policy proposals, it is important to have a good representation of the existing tax distortions. In particular, incorporating taxes will be important to consider the interaction between environmental policy and pre-existing tax distortions. Adding taxes to the dataset used to calibrate a CGE model for any particular country is not particularly difficult. What is more challenging is to construct a methodology that is consistent across countries and relies on readily available data. Mendoza, et al. [33] sets out a method by which effective tax rates on labor and capital income as well as consumption can be calculated from National Accounts data from OECD for different countries. By using OECD data, the constructed rates are consistent across countries and time and are amenable for inclusion in the GTAP data base, which is particularly poor in its representation of existing consumption and factor taxes. We follow this approach in our work. The detail of this methodology is explained in the appendix and the computed tax rates for a number of developed countries are reported in Table 4 for the year 1995 . 


\begin{tabular}{|c|c|c|c|}
\hline \multicolumn{4}{|c|}{ Table 4. Tax Rates for 1995 } \\
\hline Country & Consumption & Labor & Capital \\
\hline Denmark & $33.2 \%$ & $49.8 \%$ & $41.5 \%$ \\
\hline Finland & $26.0 \%$ & $48.4 \%$ & $35.0 \%$ \\
\hline France & $19.7 \%$ & $49.3 \%$ & $24.7 \%$ \\
\hline Germany & $16.7 \%$ & $43.5 \%$ & $24.7 \%$ \\
\hline Great Britain & $17.3 \%$ & $25.0 \%$ & $46.3 \%$ \\
\hline Italy & $15.8 \%$ & $47.0 \%$ & $32.6 \%$ \\
\hline Japan & $6.0 \%$ & $27.8 \%$ & $44.3 \%$ \\
\hline Netherlands & $18.5 \%$ & $51.2 \%$ & $28.4 \%$ \\
\hline Spain & $13.7 \%$ & $36.4 \%$ & $19.9 \%$ \\
\hline Sweden & $22.8 \%$ & $52.2 \%$ & $41.6 \%$ \\
\hline United States & $5.6 \%$ & $27.2 \%$ & $39.9 \%$ \\
\hline Source: Authors' calculations. See text for description of methodology and sources. \\
\hline
\end{tabular}

Consumption taxes, reported here inclusive of energy taxes, are high in Europe relative to Japan and the United States. The United States does not rely on a Value Added Tax as do the other countries and Japan's VAT is both a low tax VAT and subject to a relatively narrow base. The countries included in Table 4 differ in their relative taxation of capital and labor. It has long been argued that the double taxation of corporate capital income unfairly burdens capital income. The relative taxation of capital and labor in the United States in Table 4 lends support to that argument.

In terms of modeling, we have treated factor earnings from the GTAP database as gross earnings. Accordingly, we use the factor taxes schedule in Table 4 to compute 
the net factor flow services and maintain the income-expenditure balance in the database by transferring the tax revenues to the consumer as lump sum. Also the consumer expenditure on non-energy goods gross of tax has been adjusted to reflect the tax in Table 4 and the income-expenditure balance is maintained as in the factor tax case by lump sum transfer of the tax revenues to the consumer.

As noted above factor payments in GTAP are gross (of tax) payments and so overestimate the amount of capital and labor used in production. Once we break out factor taxes, we obtain the same amount of output with fewer inputs. One implication of the higher productivity of factors is that welfare in the reference scenarios was initially higher in the EPPA model with taxes than in the model without taxes, but for comparability purposes the model was rebenchmarked by lowering exogenous growth in labor productivity so that growth in welfare was nearly identical (see Table 5). Productivity growth in EPPA is essentially Harrod-neutral (i.e. labor-augmenting), ${ }^{7}$ and this exogenous growth factor is set to achieve exogenous GDP growth targets (e.g. in the reference we approximately match IMF GDP growth projections as described in Babiker et al. 2001). Without the rebenchmarking GDP growth is much more rapid than other standard forecasts.

\footnotetext{
${ }^{7}$ The Autonomous Energy Efficiency Increase (AEEI) increases productivity and we separately describe improvements in the fixed factor input to agriculture (i.e. land) that also contribute to economy-wide growth but these factors contribute only a very small share to overall growth.
} 


\begin{tabular}{|c|c|c|c|c|c|c|}
\hline \multicolumn{7}{|c|}{ Table 5. Reference Welfare in EPPA } \\
\hline & $\mathbf{2 0 0 0}$ & $\mathbf{2 0 0 5}$ & $\mathbf{2 0 1 0}$ & $\mathbf{2 0 0 0}$ & $\mathbf{2 0 0 5}$ & $\mathbf{2 0 1 0}$ \\
\hline USA & 1.253 & 1.500 & 1.785 & 1.222 & 1.447 & 1.705 \\
\hline JPN & 1.102 & 1.321 & 1.530 & 1.090 & 1.256 & 1.435 \\
\hline GBR & 1.233 & 1.451 & 1.693 & 1.209 & 1.418 & 1.648 \\
\hline DEU & 1.172 & 1.379 & 1.589 & 1.159 & 1.370 & 1.579 \\
\hline DNK & 1.334 & 1.616 & 1.938 & 1.294 & 1.588 & 1.916 \\
\hline SWE & 1.342 & 1.695 & 2.087 & 1.292 & 1.626 & 2.006 \\
\hline FIN & 1.366 & 1.768 & 2.252 & 1.352 & 1.749 & 2.227 \\
\hline FRA & 1.175 & 1.333 & 1.508 & 1.157 & 1.300 & 1.455 \\
\hline ITA & 1.140 & 1.295 & 1.453 & 1.118 & 1.259 & 1.399 \\
\hline NLD & 1.207 & 1.416 & 1.642 & 1.186 & 1.373 & 1.572 \\
\hline ESP & 1.228 & 1.484 & 1.791 & 1.205 & 1.433 & 1.693 \\
\hline REU & 1.214 & 1.415 & 1.650 & 1.188 & 1.362 & 1.556 \\
\hline OOE & 1.196 & 1.398 & 1.619 & 1.181 & 1.370 & 1.579 \\
\hline EEX & 1.157 & 1.314 & 1.490 & 1.159 & 1.316 & 1.492 \\
\hline CHN & 1.362 & 1.793 & 2.363 & 1.364 & 1.794 & 2.364 \\
\hline FSU & 1.048 & 1.220 & 1.465 & 1.050 & 1.221 & 1.466 \\
\hline IND & 1.335 & 1.757 & 2.307 & 1.336 & 1.758 & 2.307 \\
\hline EET & 1.041 & 1.134 & 1.315 & 1.041 & 1.135 & 1.315 \\
\hline DAE & 1.058 & 1.276 & 1.523 & 1.182 & 1.388 & 1.634 \\
\hline BRA & 1.177 & 1.365 & 1.581 & 1.178 & 1.365 & 1.581 \\
\hline ROW & 1.154 & 1.325 & 1.521 & 1.155 & 1.326 & 1.522 \\
\hline $\begin{array}{l}\text { Welfare is indexed at } 1.000 \text { in } 1995 . \\
\text { for country codes. Labor and capital taxes were not introduced for non-OECD } \\
\text { countries. Changes in welfare for these regions are small and due to trade effects } \\
\text { resulting from the changes in OECD countries. }\end{array}$ \\
\hline
\end{tabular}

The rebenchmarking of the model also assured that carbon emissions were not appreciably changed in the reference scenario with taxes explicitly incorporated.

\section{Kyoto Policy in a World With Tax Distortions}

At the Third Conference of the Parties (COP-3) to the United Nations

Framework Convention on Climate Change (UNFCCC) held in Kyoto, Annex B ${ }^{8}$

Parties committed to reducing, either individually or jointly, their total emissions of 
six greenhouse gases (GHGs) by at least 5 percent within the period 2008 to 2012, relative to these gases' 1990 levels.

The European Union (EU) is a full Party to the UNFCCC and a signatory of the Kyoto Protocol, has accepted a quantitative absolute reduction of 8 percent from 1990 levels of its GHG emissions. Article 4 of the Protocol allows the EU to allocate its target among the Member States. A political agreement on that redistribution was reached at the environmental Council meeting in June 1998, and is referred to as the "Burden Sharing" Agreement (BSA). Table 6 shows the BSA adopted at the environmental Council meeting by Member States on June 1998. The sharing scheme specifies emissions targets for each member country with the objective to reflect opportunities and constraints that vary from one country to another, and to share "equitably" the economic burden of climate protection.

The BSA was meant to equitably allocate the burden of the EU-wide cap among member countries. The wide difference in reduction targets for different countries reflects, to a large degree, the very different experiences of EU countries between 1990 and 1995 (the Kyoto Protocol was signed in 1997), with the UK and Germany exhibiting large declines in emissions. In the UK this was due to a significant conversion to natural gas in electric power production because of the newly available off-shore gas resources. In Germany, this was due to reunification and the resultant shut-down of inefficient industrial plants in the former East Germany.

\footnotetext{
${ }^{8}$ Annex B refers to the group of developed countries comprising of OECD (as defined in 1990), Russia
} 
Differential expected growth and relative income levels was also a factor. As we show below and as has been explored in greater detail elsewhere (Viguier, et al., 2001) even with this differentiation the cost burden varies across EU member states.

\begin{tabular}{|l|c|}
\hline \multicolumn{2}{|c|}{ Table 6. Burden Sharing Agreement for 2010 } \\
\hline \multicolumn{1}{|c|}{ Country } & Base 1990 = 100 \\
\hline Austria & 87.0 \\
\hline Belgium & 92.5 \\
\hline Germany & 79.0 \\
\hline Denmark & 79.0 \\
\hline Spain & 115.0 \\
\hline Finland & 100.0 \\
\hline France & 100.0 \\
\hline United Kingdom & 87.5 \\
\hline Greece & 125.0 \\
\hline Ireland & 113.0 \\
\hline Italy & 93.5 \\
\hline Luxembourg & 72.0 \\
\hline Netherlands & 94.0 \\
\hline Portugal & 127.0 \\
\hline Sweden & 104.0 \\
\hline Total European Union & 92.0 \\
\hline
\end{tabular}

We next report results from the EPPA model of caps on carbon emissions in Annex B to achieve the carbon reductions set forth in the Kyoto Protocol, including the United States. We model the policy by implementing carbon permits sold by each national government with revenues from permit sales recycled to the country's representative agent through a lump-sum rebate within each country. ${ }^{9}$ Below, we consider alternative revenue recycling policies. We consider carbon emissions from

and the East European Associates.

${ }^{9}$ This is equivalent to each country implementing a carbon tax (rebated lump-sum) at a level sufficient to achieve the reductions required under Kyoto. 
energy only, ignoring forest sinks for carbon and other greenhouse gases (GHGs) and

in all cases here we assume that the caps are met domestically without emissions

trading among countries. These assumptions require fairly sizable reductions in

emissions from reference so the welfare effects are evident. This differs considerably

from all that is included in the Protocol but serves as a convenient scenario against

which to evaluate the double dividend issue. ${ }^{10}$ Table 7 reports changes in welfare

relative to reference scenarios.

\footnotetext{
${ }^{10}$ As finally negotiated in Marrakech with the US not participating, allowances for extra forest sinks for carbon, other GHG abatement potential, and with full emissions trading among the countries that remained parties to the Protocol, it turns out that the Kyoto cap is only marginally binding. Excess allocation of permits to Russia, Ukraine, and other transition countries in Europe (i.e. an allocation beyond their projected emissions) means that virtually no actual reductions in any country are required if these credits can be applied in other countries as allowed under the Protocol (Babiker, et al. [4]). While that result is an important policy conclusion in itself, it means the permit price is near zero, there is little possibility for revenue generation, negligible welfare effects of the policy, and little scope for revenue recycling making it an uninteresting case for the questions we consider here. Many European countries may choose to meet their targets mainly through domestic action as the EC originally objected to full emissions trading and nothing in the Protocol requires that they use international credits to the full extent they are available.
} 


\begin{tabular}{|c|c|c|c|c|c|c|}
\hline \multicolumn{7}{|c|}{ Table 7. Welfare Costs of Kyoto (No Trading) } \\
\hline & \multicolumn{3}{|c|}{ Taxes Excluded } & \multicolumn{3}{|c|}{ Taxes Included } \\
\hline & 2010 & 2015 & 2020 & 2010 & 2015 & 2020 \\
\hline USA & -0.61 & -0.82 & -1.27 & -0.65 & -0.86 & -1.27 \\
\hline JPN & -0.63 & -0.81 & -1.11 & -0.62 & -0.80 & -1.08 \\
\hline GBR & -1.23 & -1.44 & -1.99 & -1.05 & -1.22 & -1.69 \\
\hline DEU & -0.87 & -0.90 & -1.24 & -0.77 & -0.79 & -1.09 \\
\hline DNK & -4.26 & -4.21 & -4.63 & -3.82 & -3.77 & -4.05 \\
\hline SWE & -3.63 & -4.24 & -4.91 & -3.46 & -3.98 & -4.56 \\
\hline FIN & -2.26 & -2.84 & -3.56 & -1.86 & -2.34 & -2.93 \\
\hline FRA & -0.71 & -0.95 & -1.42 & -0.70 & -0.93 & -1.36 \\
\hline ITA & -1.14 & -1.55 & -3.30 & -1.26 & -1.70 & -3.30 \\
\hline NLD & -5.08 & -5.42 & -5.98 & -4.67 & -5.11 & -5.72 \\
\hline ESP & -3.34 & -4.40 & -6.11 & -3.13 & -4.17 & -5.83 \\
\hline REU & -1.29 & -2.06 & -3.33 & -1.27 & -2.03 & -3.28 \\
\hline OOE & -2.27 & -2.67 & -2.57 & -1.96 & -2.30 & -2.20 \\
\hline EEX & -3.54 & -4.08 & -3.18 & -3.62 & -4.16 & -3.29 \\
\hline CHN & 0.27 & 0.29 & -0.14 & 0.26 & 0.27 & -0.16 \\
\hline FSU & -2.22 & -2.54 & -1.19 & -2.27 & -2.59 & -1.23 \\
\hline IND & 1.10 & 1.24 & 0.23 & 1.11 & 1.25 & 0.24 \\
\hline EET & 0.75 & 0.80 & 0.10 & 0.74 & 0.78 & 0.07 \\
\hline DAE & 0.53 & 0.53 & -0.17 & 0.53 & 0.51 & -0.20 \\
\hline BRA & 0.45 & 0.46 & 0.09 & 0.45 & 0.46 & 0.08 \\
\hline ROW & 0.13 & 0.10 & -0.22 & 0.12 & 0.07 & -0.24 \\
\hline \multicolumn{7}{|c|}{$\begin{array}{l}\text { This table reports percentage changes in EV relative to the reference scenarios (either } \\
\text { with or without taxes). Labor and capital taxes were not introduced for non-OECD } \\
\text { countries. Changes in welfare for these regions are small and due to trade effects } \\
\text { resulting from the changes in OECD countries. }\end{array}$} \\
\hline
\end{tabular}

Given the improvement in welfare in the reference we observed before rebenchmarking, we thought it possible that simply including the tax wedges might change the costs of meeting a target. We hypothesized that resource substitutions might be less costly, thus making it easier for firms to shift out of carbon intensive production in response to Kyoto. In other words, fewer resources would need to be 
shifted across sectors for a given reduction in carbon use. ${ }^{11}$ As can be seen from Table 7, there was little difference in the cost of Kyoto when simulated using the standard EPPA version and the tax version of EPPA. For the most part, the remaining differences appear due to the fact that even after rebenchmarking there remained some minor differences between the two reference scenarios. The inclusion of fuel taxes did not by itself change estimates of the cost of Kyoto policy when the carbon revenues are recycled in a lump sum manner, nor do the differences in tax rates for capital, labor, and consumption taxes appear to explain differences in estimates of the costs among countries. The standard version of EPPA includes distorting energy taxes and, elsewhere, it has been shown that the presence or absence of energy taxes does affect the cost of Kyoto substantially (Babiker, et al. [8]).

We next report on simulations in which carbon permits are used to achieve Kyoto with tax recycling of the proceeds a possibility, here focusing on only the tax version of EPPA where the results across scenarios are strictly comparable. We consider four possible uses of carbon tax revenues as described in Table 8.

\begin{tabular}{|c|c|}
\hline \multicolumn{2}{|c|}{ Table 8. Tax Recycling Scenarios } \\
\hline NRP & Lump Sum Recycling \\
\hline LRP & Labor Tax Recycling \\
\hline CRP & Non-Energy Consumer Tax Recycling \\
\hline LCRP & $\begin{array}{c}50 \% \text { Labor and } 50 \% \text { Consumer Tax } \\
\text { Recycling }\end{array}$ \\
\hline $\begin{array}{l}\text { All scenarios impose caps on carbon emissions to achieve } \\
\text { Kyoto reductions. Caps are achieved through permits sold by } \\
\text { the national governments. }\end{array}$ \\
\hline
\end{tabular}

\footnotetext{
${ }^{11}$ Without rebenchmarking the results would have been convoluted with the fact that the required reductions would have been larger in the tax version of EPPA.
} 
The first scenario returns carbon permit revenues to the representative agent in a lump sum fashion. The other three scenarios use proceeds to lower some distorting tax (or set of taxes). Table 9 reports the change in welfare in 2010 relative to the reference scenario for the various proposals. We report here only the impacts for those countries with binding commitments under the Kyoto Protocol as originally signed. ${ }^{12}$

\begin{tabular}{|l|c|c|c|c|}
\hline \multicolumn{5}{|c|}{ Table 9. Welfare Changes with Recycling } \\
\hline & NRP & LRP & CRP & LCRP \\
\hline USA & $-0.65 \%$ & $-0.49 \%$ & $-0.57 \%$ & $-0.53 \%$ \\
\hline JPN & $-0.62 \%$ & $-0.56 \%$ & $-0.54 \%$ & $-0.54 \%$ \\
\hline GBR & $-1.05 \%$ & $-0.97 \%$ & $-0.91 \%$ & $-0.94 \%$ \\
\hline DEU & $-0.77 \%$ & $-0.69 \%$ & $-0.55 \%$ & $-0.62 \%$ \\
\hline DNK & $-3.82 \%$ & $-3.54 \%$ & $-3.23 \%$ & $-3.38 \%$ \\
\hline SWE & $-3.46 \%$ & $-3.27 \%$ & $-3.03 \%$ & $-3.14 \%$ \\
\hline FIN & $-1.86 \%$ & $-1.67 \%$ & $-1.45 \%$ & $-1.55 \%$ \\
\hline FRA & $-0.70 \%$ & $-0.64 \%$ & $-0.76 \%$ & $-0.70 \%$ \\
\hline ITA & $-1.26 \%$ & $-1.08 \%$ & $-1.22 \%$ & $-1.14 \%$ \\
\hline NLD & $-4.67 \%$ & $-4.45 \%$ & $-4.87 \%$ & $-4.65 \%$ \\
\hline ESP & $-3.13 \%$ & $-3.01 \%$ & $-3.32 \%$ & $-3.16 \%$ \\
\hline REU & $-1.27 \%$ & $-1.17 \%$ & $-1.44 \%$ & $-1.31 \%$ \\
\hline OOE & $-1.96 \%$ & $-1.88 \%$ & $-1.84 \%$ & $-1.85 \%$ \\
\hline Average & $-1.94 \%$ & $-1.80 \%$ & $-1.83 \%$ & $-1.81 \%$ \\
\hline $\begin{array}{l}\text { Welfare changes are relative to the reference scenario. } \\
\text { Average is an unweighted average of the changes for the } \\
\text { countries or country groups }\end{array}$ \\
\hline
\end{tabular}

Not surprisingly, carbon reductions to achieve Kyoto with lump sum recycling reduce welfare relative to the reference scenario. Welfare losses range from a low of 0.6 percent in the United States and Japan to over 4 percent for the Netherlands. The Netherlands, Denmark, and Sweden suffer large losses because 1) they agreed to large cuts in emissions as part of the European burden sharing agreement by which the EC

\footnotetext{
${ }^{12}$ As shown elsewhere (Babiker, et al. [8]) implementation of the Kyoto Protocol can have strong effects on non-participating countries through international trade, largely through energy markets, but
} 
intends to meet its target under the Kyoto accord and 2) emissions growth in those countries since 1990 has been more rapid than in other European countries. ${ }^{13}$

The next three columns provide results for various tax reductions. In no case does welfare rise relative to the reference scenario. In other words, a strong double dividend is not possible in any of the EU countries or the United States and Japan as a result of a carbon tax to achieve Kyoto. The use of carbon taxes to reduce labor taxes does give rise to a weak double dividend. Welfare losses under the LRP scenario are always lower than under the NRP scenario.

Interestingly, the weak double dividend does not hold in all cases when carbon tax revenues are used to lower non-energy consumption taxes (CRP). France, the Netherlands, and Spain are all better off with lump-sum recycling of the carbon permit revenues than if the alternative is to reduce non-energy consumption taxes. The failure of the weak double dividend to hold simply reflects the existence of distorting energy consumption taxes that have not been reduced in this policy experiment. Intercommodity distortions are increased by a selective reduction in consumption taxation; second best considerations mean that the weak double dividend is not a universal phenomenon.

\footnotetext{
that is not the focus of the analysis presented here.

${ }^{13}$ Sweden actually was allowed a four percent growth in emissions for 2010 relative to 1990 . Its emissions in the reference scenario grow by 44 percent however. Germany and the UK agreed to very large cuts in emissions from 1990 (i.e. 20\%) but there emissions fell by large amounts between 1990 and 1995 so that these cuts do not involve as large a cut from their projected reference emissions in 2010 .
} 
We next turn to the question of whether a strong double dividend is possible by varying the labor supply elasticity. Increasing factor supply elasticities will increase the distortions from pre-existing taxes and so increase the probability of a strong double dividend. Table 10 reports welfare changes in 2010 relative to the reference scenario for differing labor supply elasticities.

\begin{tabular}{|l|c|c|}
\hline \multicolumn{3}{|c|}{$\begin{array}{c}\text { Table 10. LRP Scenario: } \\
\text { Higher Labor Supply Elasticity }\end{array}$} \\
\hline & $\mathbf{0 . 5}$ & $\mathbf{1 . 0}$ \\
\hline & $-0.27 \%$ & $0.01 \%$ \\
\hline USA & $-0.37 \%$ & $-0.12 \%$ \\
\hline JPN & $-0.63 \%$ & $-0.04 \%$ \\
\hline GBR & $-0.61 \%$ & $-0.43 \%$ \\
\hline DEU & $-3.30 \%$ & $-2.60 \%$ \\
\hline DNK & $-2.76 \%$ & $-1.78 \%$ \\
\hline SWE & $-1.25 \%$ & $-0.53 \%$ \\
\hline FIN & $-0.33 \%$ & $0.22 \%$ \\
\hline FRA & $-0.57 \%$ & $0.14 \%$ \\
\hline ITA & $-3.82 \%$ & $-2.27 \%$ \\
\hline NLD & $-1.87 \%$ & $0.01 \%$ \\
\hline ESP & $-0.67 \%$ & $0.15 \%$ \\
\hline REU & $-1.41 \%$ & $-0.64 \%$ \\
\hline OOE & resticity \\
\hline $\begin{array}{l}\text { This table reports welfare changes } \\
\text { relative to the reference scenario. }\end{array}$ \\
\hline
\end{tabular}

We draw a couple of conclusions from this analysis. First, an increase of the labor supply elasticity to 0.5 is insufficient to achieve a strong double dividend under the Kyoto Protocol. Moreover, an increase to 1.0 is required before we begin to see a possible strong double dividend. Such an estimate of the labor supply elasticity is so far out of the bounds of reasonable estimates as to preclude the existence of a strong double dividend. Second, Table 10 illustrates sharp welfare differences between the United States and many EU countries. This illustrates the important point that policy 
conclusions drawn from studies of the United States may not be transferable to EU countries (and vice versa). ${ }^{14}$

\section{Conclusion}

We began with the observation that the weak double dividend does not hold unambiguously. Relative tax distortions play an important role in this result. Revenue recycling through a tax cut can be welfare worsening relative to lump-sum recycling if the tax cut increases the relative distortion among goods. This suggests that a careful assessment of just which distortions to reduce is necessary or one can do worse than lump sum recycling. ${ }^{15}$ While this result is of theoretical interest, it turns out also to be of important practical interest. As the results from the EPPA model demonstrate, the weak double dividend is unlikely to hold for a number of European countries when policies are considered to reduce carbon emissions. This result can be traced to the high existing energy taxes in most European countries. Placing a carbon constraint on top of existing fuel taxes raises the effective tax on fuels still further and then redistributing the revenue by reducing existing taxes on labor further worsens the relative distortions between energy and labor. The result is that the interplay between carbon policies and pre-existing taxes can differ markedly across countries, depending greatly on the existing levels of different distortionary taxes that exist in an economy.

\footnotetext{
${ }^{14}$ This point is reinforced by another scenario in which we fix the labor supply elasticity at 0.25 and measure the marginal welfare cost of carbon abatement for various levels of reductions. Results reported in Babiker, et al. [5] show very different marginal welfare losses across countries.

${ }^{15}$ The EPPA model taxes capital uniformly across sectors. If the model allowed for differential taxation across sectors, additional opportunities for violations of the weak double dividend would present themselves. We thank a referee for pointing this out.
} 
Much of the empirical evidence on the double-dividend has been drawn from the US where energy taxes are very low compared to most other developed countries. Conclusions drawn from empirical analysis of the US are, therefore, particularly unlikely to apply elsewhere. In fact, globally, energy markets are some of the most heavily distorted markets. Many developed countries heavily tax consumption of fuels whereas prices on fuels are often subsidized in developing countries as a means of making energy affordable to consumers. As both energy taxes and carbon constraints are directly affecting fuel use, it is perhaps not surprising that correctly representing distortions in these markets is essential to correctly evaluating the economic impacts of climate policy. One must be cautious in extrapolating the results from a country specific analysis to other countries, and one must accurately representing existing distortions in energy markets to accurately estimate the economic impacts of climate and fiscal policy. 


\section{Appendix: Modeling Taxes in EPPA}

The basic methodology is quite simple and we illustrate it for consumption $\operatorname{taxes}^{16}$. If $\mathrm{p}$ is the consumer price for a good and $\mathrm{q}$ the producer price, then $\mathrm{p}$ and $\mathrm{q}$ are linked by the relation

$$
\mathrm{p}=\mathrm{q}+\mathrm{t}
$$

where $\mathrm{t}$ is a unit tax on the consumption good. We can re-express the unit tax as a tax exclusive ad valorem tax $(\tau)$ :

$$
\tau=\mathrm{t} / \mathrm{q}
$$

We'd like to calculate $\tau$ using observable data and so Mendoza et al. suggest the following:

$$
\tau=\frac{\mathrm{pC}-\mathrm{qC}}{\mathrm{qC}}
$$

where $\mathrm{C}$ represents aggregate consumption. The tax rate is the difference between the value of consumption in consumer prices and its value in producer prices divided by the latter. In other words, it is the tax revenue divided by the tax base (producer receipts).

For this consumption tax measure to be comprehensive, we need to capture both general and specific taxes. The tax on consumption $\left(\tau_{\mathrm{c}}\right)$ is the sum of general $\left(\mathrm{T}_{\mathrm{G}}\right)$ and specific $\left(\mathrm{T}_{\mathrm{S}}\right)$ taxes divided by private consumption $(\mathrm{C})$ and government consumption $(\mathrm{G})$ after subtracting consumption taxes paid by consumers and 
government and also subtracting compensation of government workers $(\mathrm{GW})$ which is included in G. Thus the tax rate on consumption is given by

$$
\tau_{c}=\frac{T_{G}+T_{S}}{C+G-G W-T_{G}-T_{S}}
$$

For OECD countries, collecting the required tax data is relatively straightforward as it is published annually in their Revenue Statistics series. The other required data are published for OECD countries in the National Accounts series. Obviously, OECD data can not be relied on for the 65 regions contained in the GTAP data base. United Nations National Accounts data can substitute for the OECD National Accounts. A challenge for GTAP will be to assemble the tax data across countries beyond the OECD countries. We hope to show below that the effort will have substantial payoff. Even if it is not possible to extend the tax data beyond OECD countries, it would be useful to offer an OECD module with taxes broken out.

The tax on labor income $\left(\tau_{\mathrm{L}}\right)$ requires an estimate of the individual income tax on wages. Since this is not broken out in the tax data set, Mendoza et al. begin by calculating the average tax on household income $\left(\tau_{\mathrm{h}}\right)$. This is individual income tax collections $\left(\mathrm{T}_{\mathrm{P}}\right)$ divided by wage $(\mathrm{W})$ and capital income $\left(\mathrm{K}_{\mathrm{P}}\right)$ subject to the individual income tax:

$$
\tau_{h}=\frac{T_{P}}{W+K_{P}}
$$

16 Mendoza et al. note that Razin and Sadka [35] develop these tax rates from specific tax rates faced by a representative agent in a general equilibrium model. 
They then assume that the marginal tax rate on all sources of income is the same. This is clearly a restrictive assumption but it is not clear a priori what sort of bias this imparts to the labor income tax rate. The tax on labor income is then the sum of taxes on wage income plus payroll taxes (PT) divided by total compensation (including the employer contribution for Social Security $\left.\left(\mathrm{SS}_{\mathrm{E}}\right)\right)$ :

$$
\tau_{L}=\frac{\tau_{h} W+P T}{W+S S_{E}} .
$$

Finally, the tax on capital income $\left(\tau_{\mathrm{k}}\right)$ is corporate and non-corporate tax payments divided by total surplus. ${ }^{17}$ All capital income distributed to individuals $\left(\mathrm{K}_{\mathrm{D}}\right)$ is assumed taxed at rate $\tau_{\mathrm{h}}$. In addition, corporate tax payments $\left(\mathrm{T}_{\mathrm{C}}\right)$, as well as taxes on real property and financial transactions $\left(\mathrm{T}_{\mathrm{PF}}\right)$ must be included in the numerator of the tax rate expression. The base is total operating surplus in the economy (OS):

$$
\tau_{k}=\frac{\tau_{h} K_{D}+T_{C}+T_{P F}}{O S}
$$

Mendoza et al. compare their estimates of tax rates to aggregate marginal tax rates as constructed by Joines [31], Seater [37], and Barro and Sahasakul [10] and find that the levels are different but that they move similarly over time. The MRT estimates are close to those of Joines, lower than Barro-Sahasakul and higher than Seater's. Table 4 in the main text reports our calculations of tax rates for a number of OECD countries for 1995 .

17 This tax rate assumes a constant returns to scale aggregate production function and thus the absence of economic rents. 


\section{References}

1. M. Babiker, M. Bautista, H. Jacoby and J. Reilly, Effects of Differentiating Climate Policy by Sector: A United States Example, MIT Joint Program on the Science and Policy of Global Change Report 61, Cambridge, MA. (2000).

2. M. Babiker and R. Eckaus, Rethinking the Kyoto Emissions Targets, MIT Joint Program on the Science and Policy of Global Change. Report 65, Cambridge, MA (2000).

3. M. Babiker and H. Jacoby, Developing Country Effects of Kyoto-Type Emissions Restrictions, MIT Joint Program on the Science and Policy of Global Change Report 53, Cambridge, MA (1999).

4. M. Babiker, H. Jacoby, J. Reilly and D. Reiner, The Evolution of a Climate Regime: Kyoto to Marrakech, Environmental Science and Policy forthcoming (2002).

5. M. Babiker, G. E. Metcalf and J. Reilly, Tax Distortions and Global Climate Policy, MIT Joint Program Report 85, Cambridge (2002).

6. M. Babiker, J. Reilly, R. S. Eckaus and I. Sue Wing, The MIT Emissions Prediction and Policy Analysis (EPPA) Model: Revisions, Sensitivities, and Comparisons of Results, MIT Joint Program on the Science and Policy of Global Change, Cambridge, MA. (2000).

7. M. Babiker, J. Reilly and A. D. Ellerman, Japanese Nuclear Power and the Kyoto Agreement, Journal of the Japanese and International Economies 14, 169-188 (2000).

8. M. Babiker, J. Reilly and H. Jacoby, The Kyoto Protocol and Developing Countries, Energy Policy 28, 525-536 (2000).

9. T. Barker, Achieving a 10\% Cut in Europe's CO2 Emissions Using Additional Excise Duties: Coordinated, Uncoordinated, and Unilateral Action Using the Econometric Model E3ME, Economic Systems Research 11, 401-421 (1999).

10. R. J. Barro and C. Sahasakul, Average Marginal Tax Rates From Social Security and Individual Income Tax, Journal of Business 59, 555-566 (1986).

11. A. L. Bernard and M. Vielle, Report to the MIES on the Greenhouse Effect: An Evaluation of the Kyoto Protocol with the GEMINI-E3 Model, Ministere de L'Equipment des Transports et du Logement, Commissariat a L'Energie Atomique, Paris (1999).

12. A. L. Bovenberg, Green Tax Reforms and the Double Dividend: an Updated Reader's Guide, International Tax and Public Finance 6, 421-443 (1999).

13. A. L. Bovenberg and L. H. Goulder, Environmental Tax Policy, in "Handbook of Public Economics" (A. J. Auerbach and M. Feldstein, Eds.), Elsevier Press, Amsterdam (forthcoming).

14. R. K. Boyd and M. E. Ibarrarian, Costs of Compliance with the Kyoto Protocol: A Developing Country Perspective, Energy Economics 24, 21-39 (2002). 
15. R. K. Boyd, K. Krutilla and W. Viscusi, Energy Taxation to Reduce CO2 Emissions: A Net Benefit Analysis, Journal of Environmental Economics and Management 29, 1-24 (1995).

16. C. Carraro and A. Soubeyran, Environmental Taxation and Employment in a Multi-Sector General Equilibrium Model, in "Environmental and Fiscal Reform and Unemployment" (C. Carraro and D. Siniscalco, Eds.), Kluwer Academic Publishers, London (1996).

17. A. Deaton, The Distance Function in Consumer Behaviour with Applications to Index Numbers and Optimal Taxation, Review of Economic Studies 46, 391405 (1979).

18. A. D. Ellerman and A. Decaux, Analysis of Post-Kyoto CO2 Emissions Trading Using Marginal Abatement Curves, MIT Joint Program on the Science and Policy of Global Change Report 40, Cambridge, MA (1998).

19. A. D. Ellerman and I. Sue Wing, Supplementarity: An Invitation for Monopsony?, Energy Journal. 21, 29-59 (2000).

20. Eurostat, Consumption Expenditures of Private Household in the European Union Luxembourg (1999).

21. D. Fullerton and G. E. Metcalf, Environmental Controls, Scarcity Rents, and Pre-Existing Distortions, Journal of Public Economics 80, 249-267 (2001).

22. L. H. Goulder, Effects of Carbon Taxes in an Economy with Prior Tax Distortions: An Intertemporal General Equilibrium Analysis, Journal of Environmental Economics and Management 29, 271-297 (1995).

23. L. H. Goulder, Environmental Taxation and the 'Double Dividend': A Reader's Guide, International Tax and Public Finance 2, 157- 183 (1995).

24. T. W. Hertel, Global Trade Analysis: Modeling and Applications Cambridge University Press Cambridge, MA (1997).

25. J. C. Hourcade, K. Halsnaes, M. Jaccard, W. D. Montgomoery, R. Richels, J. Robinson, P. R. Shukla and P. Sturm, A Review of Mitigation Cost Studies, in "Economic and Social Dimensions of Climate Change" (J. P. Bruce, H. Lee and E. Haites, Eds.), Cambridge University Press, Cambridge (1996).

26. J. C. Hourcade and P. R. Shukla, Global, Regional, and National Costs and Ancillary Benefits of Mitigation, in "Climate Change 2001: Mitigation" (B. Metz, O. Davidson, R. Swart and J. Pan, Eds.), Cambridge University Press, Cambridge (2001).

27. International Energy Agency, Energy Balances of OECD Countries 1995-1996 IEA Paris (1998).

28. International Energy Agency, Energy Prices and Taxes, Third Quarter 1999 IEA Paris (2000).

29. H. Jacoby, R. Eckaus, A. D. Ellerman, R. Prinn, D. Reiner and Z. Yang, CO2 Emissions Limits: Economic Adjustments and the Distribution of Burdens, MIT Joint Program on the Science and Policy of Global Change Report 9, Cambridge, MA (1997). 
30. H. D. Jacoby and I. Sue Wing, Adjustment Time, Capital Malleability and Policy Cost. Special Issue: The Costs of the Kyoto Protocol: A Multi-Model Evaluation., The Energy Journal, 73-92 (1999).

31. D. H. Joines, Estimates of Effective Marginal Tax Rates on Factor Incomes, Journal of Business 54, 191-226 (1981).

32. D. W. Jorgenson and P. Wilcoxen, Results From the Jorgenson-Wilcoxen Model, Energy Modeling Forum EMF Working Paper 12.14, Stanford, CA (1993).

33. E. G. Mendoza, A. Razin and L. L. Tesar, Effective Tax Rates in Macroeconomics: Cross-Country Estimates of Tax Rates on Factor Incomes and Consumption, Journal of Monetary Economics 34, 297-323 (1994).

34. I. W. H. Parry, Pollution Taxes and Revenue Recycling, Journal of Environmental Economics and Management 29, S64-S77 (1995).

35. A. Razin and E. Sadka, The Economy of Modern Israel: Malaise and Promise University of Chicago Press Chicago (1993).

36. J. Reilly, R. G. Prinn, J. Harnisch, J. Fitzmaurice, H. Jacoby, D. Kicklighter, P. Stone, A. Sokolov and C. Wang, Multi-Gas Assessment of the Kyoto Protocol, Nature 401, 549-555 (1999).

37. J. J. Seater, On the Construction of Marginal Federal Personal and Social Security Tax Rates in the U.S., Journal of Monetary Economics 15, 121-135 (1985).

38. R. M. Shackelton, M. Shelby, A. Cristofaro, R. Brinner, J. Yanchar, L. Goulder, D. W. Jorgenson, P. Wilcoxen, P. Pauly and R. Kaufman, The Efficiency Value of Carbon Tax Revenues, Energy Modeling Forum EMF Working Paper 12.8, Stanford, CA (1993).

39. D. Starrett, Double Dividend: Just Desserts or Pie in the Sky?, in "Green Taxes" (R. Brannlund and I.-M. Gren, Eds.), Edward Elgar, Cheltenham, UK (1999).

40. L. Viguier, M. Babiker and J. Reilly, Carbon Emissions and The Kyoto Commitment in the European Union, MIT Joint Program on the Science and Policy of Global Change Report No. 70, Cambridge, MA. (2001). 